\title{
Three-dimensional monitoring of soil water content in a maize field using Electrical Resistivity Tomography
}

\author{
L. Beff ${ }^{1}$, T. Günther ${ }^{2}$, B. Vandoorne ${ }^{1,3}$, V. Couvreur ${ }^{1}$, and M. Javaux ${ }^{1,4}$ \\ ${ }^{1}$ Earth and Life Institute, Université catholique de Louvain, Louvain-la-Neuve, Belgium \\ ${ }^{2}$ Leibniz Institute for Applied Geophysics, Hannover, Germany \\ ${ }^{3}$ Laboratoire BioGAP, Institut Supérieur d'Agriculture, Université Catholique de Lille, Université Lille Nord de France, \\ Lille, France \\ ${ }^{4}$ Institute of Bio-und Geosciences, Agrosphere IBG-3, Forschungszentrum Jülich GmbH, Jülich, Germany \\ Correspondence to: L. Beff (laure.beff@uclouvain.be)
}

Received: 26 May 2012 - Published in Hydrol. Earth Syst. Sci. Discuss.: 12 July 2012

Revised: 19 December 2012 - Accepted: 14 January 2013 - Published: 11 February 2013

\begin{abstract}
A good understanding of the soil water content (SWC) distribution at the field scale is essential to improve the management of water, soil and crops. Recent studies proved that Electrical Resistivity Tomography (ERT) opens interesting perspectives in the determination of the SWC distribution in 3 dimensions (3-D). This study was conducted (i) to check and validate how ERT is able to monitor SWC distribution in a maize field during the late growing season; and (ii) to investigate how maize plants and rainfall affect the dynamics of SWC distribution. Time Domain Reflectometry (TDR) measurements were used to validate ERT-inverted SWC values. Evolution of water mass balance was also calculated to check whether ERT was capable of giving a reliable estimate of soil water stock evolution. It is observed that ERT was able to give the same average SWC as TDR $\left(R^{2}=0.98\right)$. In addition, ERT gives better estimates of the water stock than TDR thanks to its higher spatial resolution. The high resolution of ERT measurements also allows for the discrimination of SWC heterogeneities. The SWC distribution showed that alternation of maize rows and inter-rows was the main influencing factor of the SWC distribution. The drying patterns were linked to the root profiles, with drier zones under the maize rows. During short periods, with negligible rainfall, the SWC decrease took place mainly in the two upper soil horizons and in the inter-row area. In contrast, rainfall increased the SWC mostly under the maize rows and in the upper soil layer. Nevertheless, the total amount of rainfall during the growing season was not sufficient to modify the SWC patterns induced by the maize rows. During
\end{abstract}

the experimental time, there was hardly any SWC redistribution from maize rows to inter-rows. Yet, lateral redistribution from inter-rows to maize rows induced by potential gradient generates SWC decrease in the inter-row area and in the deeper soil horizons.

\section{Introduction}

The soil water content (SWC) controls important physical, chemical and biological processes such as: plant growth, solute transport, rainfall, runoff, erosion, and ultimately pedogenesis (Western et al., 2003). Its spatial and temporal variability is governed by the variability of soil properties and by the heterogeneity of the boundary conditions, including the water sink/sources. The SWC distribution dynamics is therefore linked to spatial patterns of the processes generating/decreasing variability (Teuling and Troch, 2005). The SWC distribution affects and is affected by various hydrological processes such as the partitioning of rainfall between infiltration and runoff (Merz et al., 2006; Norbiato et al., 2009), drainage, pollutant dispersion (Flury et al., 1995) and groundwater recharge. These processes affect agricultural activities such as irrigation scheduling (Clothier and Green, 1994), precision farming or the control of groundwater pollution (Mooney and Morris, 2008).

At the field scale, crops are one of the main factors that affect SWC distribution. Amongst others, plant canopy influences the partitioning of rainfall at the soil surface (Hupet 
and Vanclooster, 2005), root water uptake generates drying patterns locally at the plant scale (Coelho and Or, 1999; Li et al., 2002; Green et al., 2006; Javaux et al., 2008) and also at the field scale (Hupet and Vanclooster, 2002, 2005; Oliveira et al., 2005; Garré et al., 2011) and root channels may induce preferential fluxes (Gish et al., 1998; Devitt and Smith, 2002). All these factors create SWC heterogeneities in three dimensions (3-D). The proper understanding of the drivers of SWC distribution dynamics is therefore crucial for accurate modelling (Western et al., 2003). Yet, quantifying soil moisture in unsaturated environments is difficult due to the complexity of unsaturated hydrologic systems and problems associated with obtaining accurate and spatially representative measurements of soil moisture in a heterogeneous environment (Schwartz et al., 2008). It is therefore challenging to quantify the SWC variability at the field scale.

Classical methods such as gravimetric measurements with soil cores (Sharp and Davies, 1985), neutron probes (Hupet and Vanclooster, 2002; Koumanov et al., 2006) or Time Domain Reflectometry (TDR) (Jacques et al., 2001; Hupet and Vanclooster, 2002; Robinson et al., 2003; Walker et al., 2004) are known to determine correctly the SWC. The advantage of these methods is their robustness, but they give only local measurement. Moreover, gravimetric measurements are destructive and TDR installation induces soil perturbation. In contrast, remote sensing methods cover large areas without soil perturbation. However, they suffer from several disadvantages. Measurement capabilities are limited to a few centimetres' depth, where there is dense vegetation cover and by soil roughness, and the within-pixel soil moisture variability cannot be obtained (Minet, 2011). Proximal soil moisture sensing, as ground penetrating radar (GPR), electromagnetic induction (EMI) and ground-based radiometers, make possible the characterization of soil moisture at an intermediate scale between remote sensing foot print and the small spatial extent of a local measurement. However, proximal soil moisture sensors (i.e. GPR and EMI) give only measurements in two dimensions (2-D). Moreover, the performance of GPR decreases in electrically conductive media such as fine-textured soils (Garré et al., 2011).

During the two last decades, Electrical Resistivity Tomography (ERT) has been used in the determination of transport processes in soils and SWC distribution. This technique was successfully used in solute transport experiments in a bare soil lysimeter (Binley et al., 1996; Koestel et al., 2008, 2009a,b; Garré et al., 2010), in large experimental tanks (Slater et al., 2002), in the field (Kemna et al., 2002; Cassiani et al., 2006), and in a forest (Oberdörster et al., 2010). Given the many factors influencing the soil electrical resistivity (Samouelian et al., 2005), soil conductivity was first used as a proxy for water content (Michot et al., 2001, 2003; Srayeddin and Doussan, 2009). However, more recently, a few studies tried to obtain the actual SWC distribution validated with TDR probes. Brunet et al. (2010) and Schwartz et al. (2008) inferred 2-D SWC maps along transects. Garré et al. (2012) developed a methodology to measure the SWC dynamics in a cropped field. Werban et al. (2008) monitored 2-D electrical resistivity changes due to root water uptake in a $0.4 \mathrm{~m} \times 0.5 \mathrm{~m}$ plot. Garré et al. (2011) investigated the 3 -D soil water depletion in a cropped lysimeter. These studies open interesting perspectives in using ERT for investigating the impact of plant on SWC dynamics. However, to our knowledge, no studies have focused yet on quantitatively monitoring the 3-D evolution of SWC in a cropped field so far.

This study was conducted to determine the SWC distribution and evolution at the plot-scale during the late growing season of maize and to investigate how maize plants affect SWC patterns. This paper aims at (i) presenting and validating a methodology for using ERT at the plot scale, and (ii) investigating how rainfall and root water uptake affect SWC distribution at that scale.

\section{Material and methods}

\subsection{Experimental site}

The experiment was conducted between 23 July and 21 September 2009 in a field of 1.6 ha located in Corroy-leGrand (Belgium), in the loamy region. The field was cropped with maize (Zea Mays L.) from 14 April 2009 to 22 September 2009. Maize was sown with a row-spacing of $75 \mathrm{~cm}$ and around $13 \mathrm{~cm}$ in the row $\left(100000\right.$ plants ha $\left.^{-1}\right)$. At the beginning of the experimental time (23 July 2009), maize plants were $2.35 \mathrm{~m}$ high and at the end of the experimental time (21 September 2009), they were about $2.65 \mathrm{~m}$ high. The flowering started on 21 July 2009 and the plants were mature for silage at harvest time, on 22 September 2009. This field was relatively flat, with slopes ranging between $0.2 \%$ and $0.5 \%$ (Weynants, 2011). The soil was classified as a Haplic Luvisol (Soil Atlas of Europe, 2005) according to the FAO classification system and considered a well-drained loam (Aba(b)), according to the Belgian soil classification. Three soil horizons were identified (Fig. 1). The Ap1 horizon $(0-35 \mathrm{~cm})$ had a strong blocky angular structure and contained many roots. The Bt1 horizon $(37-75 \mathrm{~cm})$ had a strong blocky angular structure. The Bt2 horizon $(>75 \mathrm{~cm})$ had a weak blocky structure. A plough pan layer $(35-37 \mathrm{~cm})$, which is more resistant to penetration than the above horizon, was observed between the Ap1 and $\mathrm{Bt} 1$ horizons. The properties of the soil horizons are presented in Table 1. More information on this soil can be found in Weynants (2011).

\subsection{Experimental plot}

In the field, an experimental plot of $2.5 \mathrm{~m} \times 17 \mathrm{~m}$ was delimited and equipped in mid-July 2009 with 14 TDR probes, 132 surface and in-depth electrodes for conducting ERT, 7 temperature probes and 7 water tensiometers (Fig. 2). 


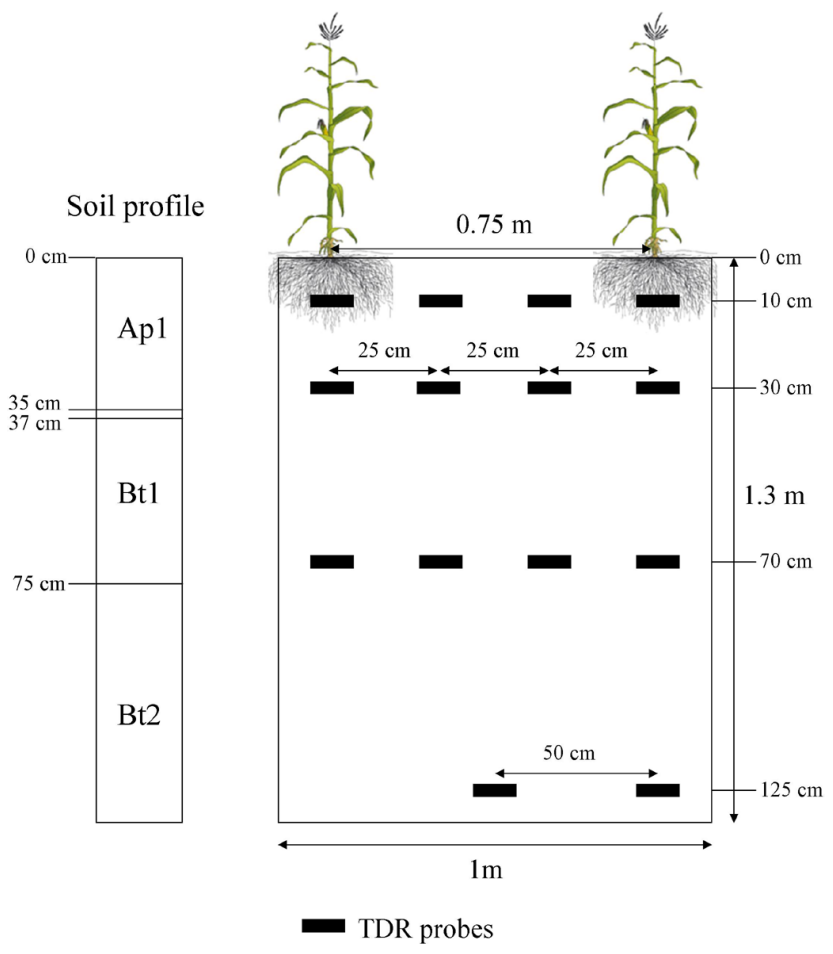

Fig. 1. Depths of the soil horizons (Ap1, plough pan layer, Bt1 and $\mathrm{Bt} 2)$ and position of TDR probes.

The seven water tensiometers were vertically inserted near the TDR probe trench to monitor water potential gradient and estimate water fluxes (at depths $7.5 \mathrm{~cm}, 11.5 \mathrm{~cm}, 33 \mathrm{~cm}$, $68.5 \mathrm{~cm}, 132.5 \mathrm{~cm}, 137 \mathrm{~cm}$ and $140 \mathrm{~cm}$, with a horizontal spacing of $15 \mathrm{~cm}$ between each tensiometers). The tensiometers were installed in July in the middle of the inter-row to avoid damaging maize plants (Fig. 2).

The root colonization of soil in 2-D was characterized using the Tardieu profile method (Tardieu, 1988). A trench was dug perpendicular to maize rows (including 2 rows and 2 inter-rows) at the border of the experimental plot (Fig. 2). An iron grid $(0.5 \mathrm{~m}$ width and $0.5 \mathrm{~m}$ depth) with a mesh of $5 \mathrm{~cm}$ was then fixed to the vertical soil profile, starting from the upper left corner and then moved to cover the whole soil profile ( $1.5 \mathrm{~m}$ width and $1 \mathrm{~m}$ depth). In each $5 \mathrm{~cm} \times 5 \mathrm{~cm}$ cell, the number of root segments was counted. These root segments were part of the total root system, which reached/impacted this vertical plane, and were called root impacts (Vandoorne et al., 2012). The roots repartition was determined with 2-D vertical maps of root impacts. The three root profiles (13 August, 27 August and 18 September 2009) were performed with a spacing ranging from $13 \mathrm{~cm}$ to $26 \mathrm{~cm}$ between each root profile in order to get two maize rows lined up.

The agro-climatic variables, i.e. temperatures, relative humidity, shortwave radiation, wind speed and rainfall were monitored in a meteorological weather station situated $1.2 \mathrm{~km}$ away from the study site. As the plot was

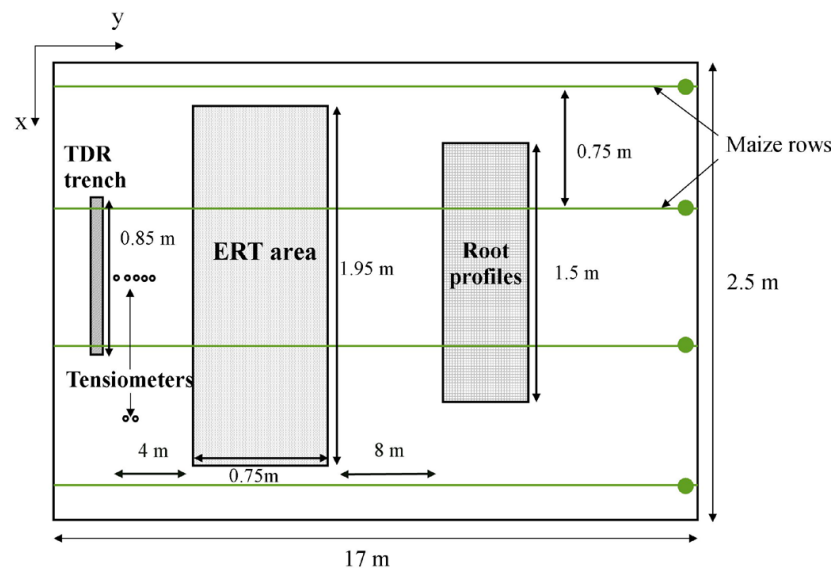

Fig. 2. Scheme of the experimental plot, with position of the TDR trench containing the 14 TDR probes, ERT area with the ERT electrodes, tensiometers and place where the root profiles were made. The green lines represent the maize rows.

flat and ploughed before sowing, runoff was considered as null. The crop evapotranspiration (ETC) (Fig. 5) was determined using the single crop coefficient $\left(K_{\mathrm{c}}\right)$ approach and the reference evapotranspiration $\left(\mathrm{ET}_{0}\right)$, calculated using the Penman-Monteith's equation (Allen et al., 1998) based on the meteorological station data. The drainage was estimated by the use of deep tensiometers $(132.5 \mathrm{~cm}$ and $140 \mathrm{~cm})$ for the hydraulic head gradient and the unsaturated hydraulic conductivity obtained using the Mualem-van Genuchten model (van Genuchten, 1980) with the parameters obtained by multistep outflow experiments presented in Table 1 (Weynants, 2011).

\subsection{Time Domain Reflectometry}

The TDR method was used to monitor SWC with a high time resolution $(\Delta t=1 \mathrm{~h})$. Fourteen TDR probes ( 3 rods, $30 \mathrm{~cm}$ long, $0.5 \mathrm{~cm}$ rod diameter, $2 \mathrm{~cm}$ rod spacing) were horizontally installed at 4 different depths $(10 \mathrm{~cm}, 30 \mathrm{~cm}, 70 \mathrm{~cm}$ and $125 \mathrm{~cm}$ ) (Fig. 1) in a trench of $1 \mathrm{~m}$ width and $1.30 \mathrm{~m}$ depth that was filled up after TDR installation. The TDR probes were inserted perpendicularly to the maize rows with 7 probes below maize rows and 7 in the inter-rows (Fig. 1). The probes were connected to a TDR multiplexer (Campbell SDMX50, Campbell Scientific Lt., UK) controlled by an automatic data logger (CR10X, Campbell Scientific Lt., UK). TDR signals were generated and automatically analyzed by means of a TDR100 system (Campbell Scientific Lt., UK). Measurements were monitored during 61 days under natural boundary conditions. TDR probes were calibrated using the Heimovaara (1993) method following the protocol described by Garré et al. (2008).

Topp's equation (Topp et al., 1980) was used to determine SWC, $\theta_{\text {TDR }}\left[\mathrm{cm}^{3} \mathrm{~cm}^{-3}\right]$, from the apparent dielectric constant, $\kappa_{\mathrm{a}}$, measured by TDR. 
Table 1. Textural and hydraulic properties for each soil horizon (Weynants, 2011). S, L and C respectively represent the percentage of sand, loam and clay; BD is the soil bulk density; $\theta_{\mathrm{r}}$ and $\theta_{\mathrm{S}}$ are the saturated and the residual SWC, respectively. $\alpha, n$, and $l$ are the Mualem-van Genuchten parameters.

\begin{tabular}{|c|c|c|c|c|c|c|c|c|c|c|c|}
\hline $\begin{array}{l}\text { Soil } \\
\text { Horizon }\end{array}$ & $\begin{array}{r}\mathrm{S} \\
{[\%]}\end{array}$ & $\begin{array}{r}\mathrm{L} \\
{[\%]}\end{array}$ & $\begin{array}{r}\mathrm{C} \\
{[\%]}\end{array}$ & $\begin{array}{r}\text { BD } \\
{\left[\mathrm{g} \mathrm{cm}^{-3}\right]}\end{array}$ & $\mathrm{pH}$ & $\begin{array}{r}\theta_{\mathrm{s}} \\
{\left[\mathrm{cm}^{3} \mathrm{~cm}^{-3}\right]}\end{array}$ & $\begin{array}{r}\theta_{\mathrm{r}} \\
{\left[\mathrm{cm}^{3} \mathrm{~cm}^{-3}\right]}\end{array}$ & $\begin{array}{r}K_{\mathrm{S}} \\
{\left[\mathrm{cm} \mathrm{min}^{-1}\right]}\end{array}$ & $\begin{array}{r}\alpha \\
{\left[\mathrm{cm}^{-1}\right]}\end{array}$ & $\begin{array}{r}n \\
{[-]}\end{array}$ & $\begin{array}{r}l \\
{[-]}\end{array}$ \\
\hline Ap & 3 & 76 & 21 & 1.42 & 7.1 & 0.442 & 0.145 & 0.079 & 0.035 & 1.265 & 3.954 \\
\hline Bt1 & 1 & 67 & 32 & 1.44 & 7.7 & 0.445 & 0.200 & 0.114 & 0.106 & 1.219 & 1.206 \\
\hline $\mathrm{Bt} 2$ & 1 & 74 & 25 & 1.50 & 7.7 & 0.440 & 0.028 & 0.997 & 0.094 & 1.100 & 1.734 \\
\hline
\end{tabular}

$$
\begin{aligned}
\theta_{\mathrm{TDR}}= & -5.3 \times 10^{-2}+2.92 \times 10^{-2} \kappa_{\mathrm{a}} \\
& -5.5 \times 10^{-4} \kappa_{\mathrm{a}}^{2}+4.3 \times 10^{-6} \kappa_{\mathrm{a}}^{3}
\end{aligned}
$$

Topp's equation was verified for our soil type with undisturbed soil samples. The root mean square error (RMSE) of $0.0204 \mathrm{~cm}^{3} \mathrm{~cm}^{-3}$ between real and calculated SWC indicates that Eq. (1) is suitable for this soil.

\subsection{Electrical Resistivity Tomography}

ERT was used to monitor the three-dimensional distribution of the bulk electrical conductivity $\left(\mathrm{EC}_{\mathrm{b}}\right)$. Seventy-six surface electrodes (4-cm depth) and eight PVC sticks with seven electrodes each were inserted into the soil to form a regular grid of $1.95 \mathrm{~m} \times 0.75 \mathrm{~m}$ with an electrode spacing of $0.15 \mathrm{~m}$ (Fig. 3). Each stick consisted of a PVC tube with 7 stainless steel rings (22-mm height), used as electrodes, and positioned at 7 depths $(5 \mathrm{~cm}, 15 \mathrm{~cm}, 30 \mathrm{~cm}, 50 \mathrm{~cm}, 75 \mathrm{~cm}, 105 \mathrm{~cm}$ and $140 \mathrm{~cm}$ ). The stainless steel rings were a little bit larger (diameter of $46 \mathrm{~mm}$ ) than the PVC tube (diameter of $45 \mathrm{~mm}$ ) to improve electrode-soil contact.

\subsubsection{Data acquisition}

ERT measurements were conducted between 13 August and 18 September 2009. During this time, 9 measurement frames were performed using the ten-channel SYSCAL Pro instrument with the corresponding relay boxes (SWITCH Pro) for electrode switching to carry out the ERT measurements (Iris Instruments, France).

Based on Bing and Greenhalgh (2000) and in-field tests, a measurement scheme adapted to our experimental setup was developed. A combination of various measurement types was used: (i) dipole-dipole measurements between the electrodes above 30-cm depth (76 surfaces electrodes and 24 upper sticks electrodes) with first, second and third spacing; (ii) Wenner measurements with stick electrodes; (iii) cross-stick measurements; and (iv) cross measurements between surface electrodes and stick electrodes. In order to assess data quality, all these measurements were realized in the normal and the reciprocal mode (LaBrecque et al., 1996; Slater et al., 2000; Koestel et al., 2008; Garré et al.,

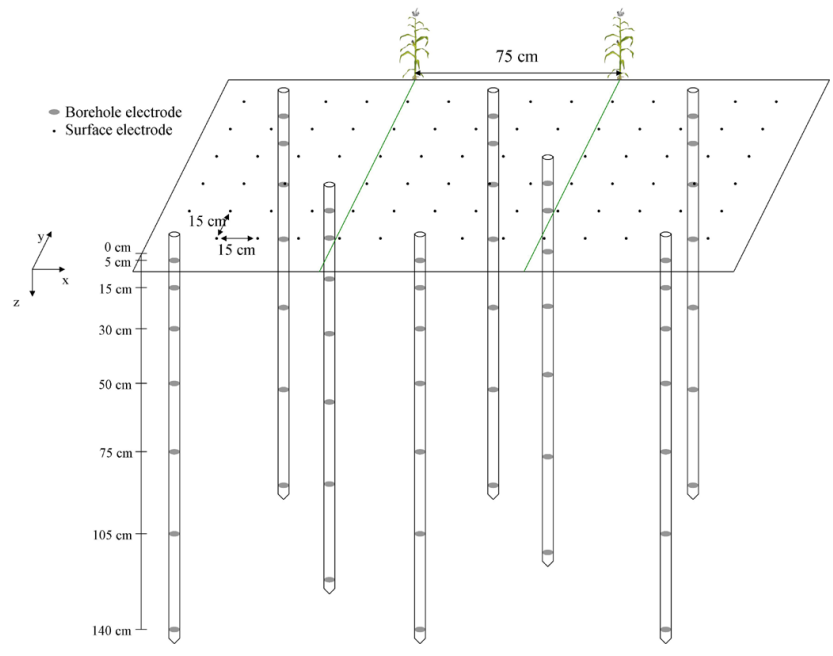

Fig. 3. Scheme of the ERT electrode positions. The tubes with black rings represent the PVC sticks with the ring electrodes; the black dots represent the surface electrodes. The green lines correspond to the maize rows.

2010), where current and potential dipoles were switched. The measurement scheme took seven hours to run and contained 12664 (normal and reciprocal) measurements.

\subsubsection{Data filtering}

First, all data outside of the predefined bounds of measured voltage, injection current and geometric factor (larger than $400 \mathrm{~m}$ ) were removed. Then, data associated to a high stacking factor (above $2 \%$ ) given by the instrument were eliminated. The stacking factor (Slater et al., 2000) is the standard deviation of maximum 4 stacks of a measurement. The next step was to eliminate the data with a reciprocal error in $\Omega\left(e_{i}=R_{\mathrm{n}, i}-R_{\mathrm{r}, i}\right)$, the difference between the normal $\left(R_{\mathrm{n}, i}\right)$ and the reciprocal measurements $\left(R_{\mathrm{r}, i}\right)$, higher than $2 \%$ of the mean resistance $\left(R_{i}\right)$ in $\Omega$. The mean between the normal and reciprocal measurements was then associated to each injection pair. Eventually the same 1994 quadripole measurements were kept for each frame. 


\subsubsection{ERT inversion}

To assess the soil $\mathrm{EC}_{\mathrm{b}}$ distribution, a three-dimensional inversion of the ERT data obtained by the measurements was used. The ERT measurements in $\Omega\left(R_{i}\right.$, with $i=1, \ldots$, $N$ ) were inverted for each frame using a difference inversion (LaBrecque and Yang, 2001), with the first data set as reference. The code used for the inversion was BERT (Günther et al., 2006; Rücker et al., 2006) with an errorweighted, smoothness-constrained, Occam-type algorithm. The algorithm finds the smoothest distribution of logarithmized resistivities (in $\Omega \mathrm{m})\left(\log \left(\rho_{j}\right)\right.$, with $\left.j=1,2, \ldots, M\right)$ which fits the measured data to a specified relative error, $\varepsilon_{i}$ (-). A Gauss-Newton scheme with global regularization was used to minimize the following objective function:

$\phi=\|\mathbf{D}[\boldsymbol{d}-\boldsymbol{f}(\boldsymbol{m})]\|_{2}^{2}+\lambda\left\|\mathbf{C}\left(\boldsymbol{m}-\boldsymbol{m}_{0}\right)\right\|_{2}^{2}$,

where $d$ is the data vector, given by $d_{i}=\log \left(G_{i} R_{i}\right)$ with $i=1,2, \ldots, N$, and $G_{i}$ the geometric factor (in $\mathrm{m}$ ); $\boldsymbol{f}(\boldsymbol{m})$ is the forward response for the model vector $\boldsymbol{m}$, given by $m_{j}=\log \left(\rho_{j}\right)$; and $f_{i}(\boldsymbol{m})=\log \left(\rho_{\mathrm{a}, i}\right)$, where $\rho_{\mathrm{a}, i}(\Omega \mathrm{m})$ is the apparent resistivity of the forward model. $\boldsymbol{m}_{0}$ is the starting and reference model (homogeneous for the first time step and its result for the others), and $\lambda(-)$ a regularization parameter that determines the amount of smoothing imposed on $\boldsymbol{m}$ during the inversion. In this study, the $\lambda$ was fixed for all the inversion to 50 . This value was chosen after realizing inversion tests by decreasing lambda from 100 to 10 . The value of 50 for lambda was the result of a compromise between data misfit and the roughness of the images.

The matrix $\mathbf{C}$ represents a discrete approximation of a partial differential operator of first order (Günther et al., 2006), and $\mathbf{D}$ is the error weighting matrix, given by

$\mathbf{D}=\operatorname{diag}\left[1 / \log \left(1+\varepsilon_{i}\right)\right]$.

The errors were assumed to be composed of a percentage error of several per cent $(p)$ and a voltage error $(\delta U)$ (Friedel, 2003), with $U$ the measured potential difference (in V):

$\varepsilon_{i}=p \%+\frac{\delta U}{U_{i}}$.

To determine the error level that should be used in the inversions, an error analysis using the error model of Koestel et al. (2008) (based on reciprocal data) was realized. The analysis for each data set separately gave us a $p$ error ranging from $1 \%$ to $3 \%$ and a $\delta U$ error of $0.5 \mathrm{mV}$. When all the data sets together were analyzed, a $p$ error of $1.7 \%$ and a $\delta U$ error of $0.76 \mathrm{mV}$ were obtained. The percentage error of $1.7 \%$ was relatively small. It was then increased to account for the error sources that were not exposed by reciprocal error (Udphuay et al., 2011). In this study, a percentage error $p$ of $2.7 \%$ and a $\delta U$ of $0.8 \mathrm{mV}$ were used in the inversions.

The deep electrodes of the system are ring electrodes located on a PVC stick. But, for the inversion, they were considered point electrodes. To make this assumption, the effect of the electrodes size on the results of the inversion was first verified. The finite size of electrodes was accounted for by taking the geometric factors of a complete electrode model (Rücker and Günther, 2011) with real geometries. We observed that the results considering the real size of electrodes or point electrodes were similar.

To determine the quality of the inversion of ERT data, the relative root mean square error (rrms) and the $\chi^{2}$ were calculated as

$\mathrm{rrms}=\sqrt{\frac{\sum_{i}\left[\frac{d_{i}-f_{i}(\boldsymbol{m})}{d_{i}}\right]^{2}}{N}} \cdot 100 \%$

$\chi^{2}=\frac{\sum_{i}\left[\frac{d_{i}-f_{i}(\boldsymbol{m})}{\varepsilon_{i}}\right]^{2}}{N}$.

Except for the first data frame, which was used as reference during the inversion, the $\chi^{2}$ was below 3 and the rrms was below $9 \%$.

To assess ERT spatial resolution, an indirect approach based on the sensitivity was used in this study (Kemna et al., 2002; Binley and Kemna, 2005). The coverage, which is the sum of all (absolute values of the) sensitivities for a given model parameter (Günther, 2004) was used in analogy to linear tomography problems. Because the cell sizes were not equal for all model parameters, the coverage was weighted by dividing it for each cell, $j$, by its size, $\eta_{j}$ (in $\mathrm{m}^{3}$ ). The coverage, $\operatorname{cov}_{j}\left(\right.$ in $^{-3}$ ), was calculated for each cell $j$ of inverted resistivity as shown in Eq. (7). The obtained coverage was then normalized and put in log-scale for the figures.

$\operatorname{cov}_{j}=\frac{\sum_{i=1}^{N}\left|\frac{\partial f_{i}(\boldsymbol{m})}{\partial m_{j}}\right|}{\eta_{j}}$

\subsection{Determination of the pedoelectrical relationship}

Pedoelectrical models link $\mathrm{EC}_{\mathrm{b}}$ to variables influencing this conductivity: surface conductivity of the soil matrix, pore water conductivity, porosity of the soil, temperature and water content (Archie, 1942; Waxman and Smits, 1968; Rhoades et al., 1989; Revil et al., 1998). Three pedoelectrical relationships were derived, one per soil horizon (Ap1, Bt1 and Bt2), based on the simplified Waxman and Smits's model (Garré et al., 2011):

$\sigma=a \theta^{c}+b$,

where $\sigma\left(\mathrm{S} \mathrm{m}^{-1}\right)$ is $\mathrm{EC}_{\mathrm{b}}, \theta\left(\mathrm{cm}^{3} \mathrm{~cm}^{-3}\right)$ is $\mathrm{SWC}$, and $a$ $\left(\mathrm{S} \mathrm{m}^{-1}\right), b\left(\mathrm{~S} \mathrm{~m}^{-1}\right)$ and $c(-)$ are fitting parameters. This simplified model could be used since the soil solution electrical conductivity is assumed to remain constant. For determining 
the parameters of Eq. (8), a TDR dataset from the same field, acquired during another field campaign in 2010, was used.

The TDR bulk electrical conductivity ( $\sigma_{\mathrm{TDR}}$ in $\mathrm{S} \mathrm{m}^{-1}$ ) was obtained from TDR signal attenuation using the following equation (Heimovaara, 1993; Mallants et al., 1996):

$\sigma_{\mathrm{TDR}}=\frac{K_{\mathrm{p}}}{R_{\mathrm{TDR}}-R_{\mathrm{cable}}}$,

where $K_{\mathrm{p}}\left(\mathrm{m}^{-1}\right)$ is the cell constant of the TDR probe, and $R_{\text {cable }}(\Omega)$ is the resistance associated to the cable tester, multiplexers, and connecters. The value of $R_{\mathrm{TDR}}(\Omega)$ is derived from $\rho_{\infty}$, the reflection coefficient at very long time, and is defined as

$R_{\mathrm{TDR}}=Z_{C} \frac{\left(1+\rho_{\infty}\right)}{\left(1-\rho_{\infty}\right)}$,

where $Z_{C}(\Omega)$ is the impedance of the TDR device, multiplexers, and cables. Both $K_{\mathrm{p}}$ and $R_{\text {cable }}$ were determined for each probe individually using calibration measurements (Garré et al., 2008). A temperature correction was applied to obtain the $\mathrm{EC}_{\mathrm{b}}$ at $25^{\circ} \mathrm{C}\left(\sigma_{25}\right)$ from $\mathrm{EC}_{\mathrm{b}}$ at the soil temperature $T$ in ${ }^{\circ} \mathrm{C}(\sigma)$, so that

$\sigma_{25}=\frac{\sigma}{1+0.02(T-25)}$.

The three pedoelectrical relationships were applied on the $\mathrm{ECb}$ at $25^{\circ} \mathrm{C}$, obtained by the inversion of ERT measurements, to transform it into SWC.

\subsection{Validation of ERT soil water content}

To validate ERT in a global way, the soil water stock change estimated from two ERT measurements were compared with mass balance estimates obtained from independent measurements:

$P-D-\mathrm{ETC}-\Delta S=0$,

where $P$ is the effective rainfall $(\mathrm{mm}), D$ is the drainage $(\mathrm{mm})$, ETC is the crop evapotranspiration $(\mathrm{mm})$ and $\Delta S$ is the variation of SWC stock $(\mathrm{mm})$ between the time $(t)$ and the previous time $(t-1)$. The water stock was obtained by integrating ERT SWC from 0 to $140 \mathrm{~cm}$ depth. As an additional check, the TDR data from the 2009 campaign was also used to validate the stock from ERT data. The TDR SWC measured at 4 depths $(10 \mathrm{~cm}, 30 \mathrm{~cm}, 70 \mathrm{~cm}$ and $125 \mathrm{~cm})$ was interpolated for the whole soil profile (from 0 to $140 \mathrm{~cm}$ depth).

To assess the quality of the pedophysical relationship, we compared SWC obtained by ERT and TDR. For that, the SWC measured by all TDR probes was averaged at each depth (Fig. 1) during ERT measurements (between $9 \mathrm{~h}$ and $16 \mathrm{~h})$. Similarly, the SWC situated in the ERT voxels corresponding to the TDR depths $(10 \mathrm{~cm}, 30 \mathrm{~cm}, 70 \mathrm{~cm}$ and $125 \mathrm{~cm}$ depth) was averaged. Assuming that the actual SWC at TDR and ERT locations was the same, the averaged SWC measured by both methods should be the same if the pedoelectrical relationship is correct.

To verify that ERT was able to map horizontal SWC variability, we discriminated the SWC evolution under the maize rows and under the inter-rows. TDR measurements were realized directly in these two distinct areas (Fig. 1). For ERT, a row area corresponding to $20 \mathrm{~cm}$ from each side of the maize row and an inter-row area of $35 \mathrm{~cm}$ in the middle were considered. For each measurement time, the SWC obtained in each cell was averaged for the row area and the inter-row area.

\section{Results and discussion}

\subsection{Pedoelectrical relationships}

The three pedoelectrical relationships obtained from TDR calibration are shown in Fig. 4. They were used to transform the ERT $\mathrm{EC}_{\mathrm{b}}$ in SWC with the parameters of the simplified Waxman and Smits's model presented in Table 2. The $\mathrm{EC}_{\mathrm{b}}$ and SWC ranges of the first soil horizon are larger than for the two other soil horizons, demonstrating that the first soil horizon experienced larger variations of SWC. The pedoelectrical relationship for the third horizon is relatively flat for the $\mathrm{EC}_{\mathrm{b}}$ range encountered during experimental time (between $0.01 \mathrm{~S} \mathrm{~m}^{-1}$ and $0.07 \mathrm{~S} \mathrm{~m}^{-1}$ ). This denotes a high accuracy in SWC prediction in the third soil horizon for this range of $\mathrm{EC}_{\mathrm{b}}$. An attempt was made to split the pedoelectrical functions with and without the presence of roots, without any improvement, in contrast to the observations made by Werban et al. (2008), who observed two distinct pedoelectrical relationships in presence or absence of roots.

In each soil layer, the observed RMSE (Table 2) were close to the ones obtained by Garré et al. (2011) and similar to the RMSE obtained with the TDR SWC calibration $\left(\mathrm{RMSE}=0.024 \mathrm{~cm}^{3} \mathrm{~cm}^{-3}\right)$. It suggests that a part of the variation may be influenced by TDR uncertainty.

\subsection{Validation of soil water content distribution measured by ERT}

\subsubsection{Water balance}

Figure 5 shows the evolution of the boundary conditions of the experimental plot ( $P, D$ and ETC) and the water stock evolution for TDR and ERT measurements for the whole soil profile (between 0 and $140 \mathrm{~cm}$ depth). During the measurement time on this studied plot, the bottom boundary fluxes $(D)$ were small compared to the top boundary fluxes ( $P$ and ETC). Positive $D$, i.e. capillary rise, was observed most of the time. During the experimental period, the TDR water stock had a general decreasing trend, ranging from $453 \mathrm{~mm}$ (on 24 July) to $417 \mathrm{~mm}$ at the end of the period (21 September 2009), due to ETC, with local increases due to the rainfall events. The water stock estimated from ERT was higher 

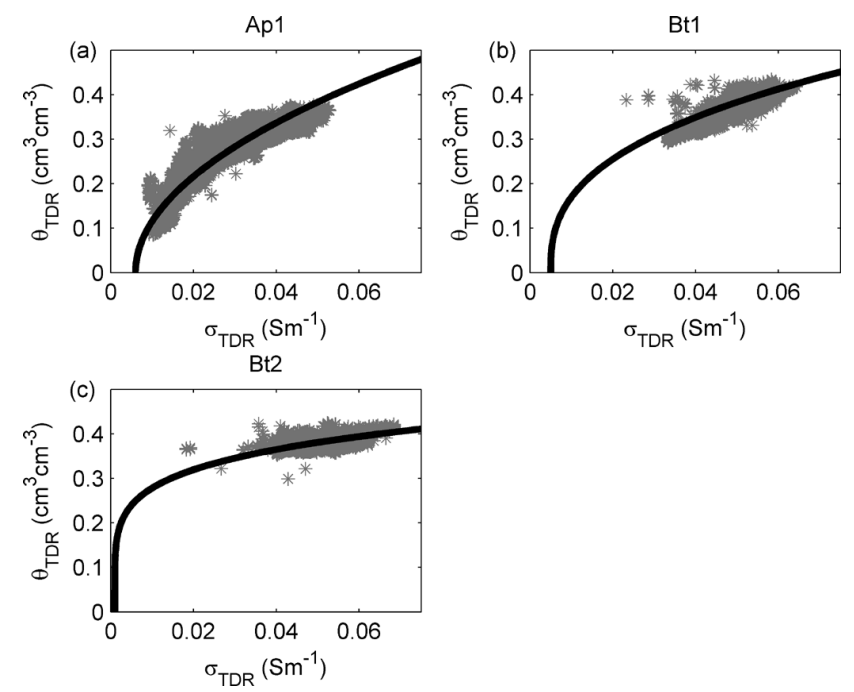

Fig. 4. $\mathrm{EC}_{\mathrm{b}}\left(\sigma_{\mathrm{TDR}}\right)$ and $\mathrm{SWC}\left(\theta_{\mathrm{TDR}}\right)$ for TDR measurements realized in the three soil horizons in 2010 (Ap1 horizon a, Bt1 horizon b, and Bt2 horizon c). The black curves represent the simplified Waxman and Smits model that fits the $\sigma_{\mathrm{TDR}}-\theta_{\mathrm{TDR}}$ couples.

Table 2. Parameters for the simplified Waxman and Smits model and RMSE for each of the three soil horizons.

\begin{tabular}{lrrrr}
\hline Horizon & $a\left(\mathrm{~S} \mathrm{~m}^{-1}\right)$ & $b\left(\mathrm{~S} \mathrm{~m}^{-1}\right)$ & $c(-)$ & $\operatorname{RMSE}\left(\mathrm{cm}^{3} \mathrm{~cm}^{-3}\right)$ \\
\hline Ap1 & 0.3 & 0.006 & 2 & 0.024 \\
Bt1 & 0.6 & 0.005 & 2.7 & 0.020 \\
Bt2 & 9.0 & 0.001 & 5.4 & 0.011 \\
\hline
\end{tabular}

than the one obtained by TDR. The deviation between ERT and TDR soil water storage ranged between $2.4 \mathrm{~mm}$ and $15.2 \mathrm{~mm}$. This is in the same range than the observations made by Hupet et al. (2004), who showed that uncertainty in a soil water storage estimate for their considered experimental measurements in terms of standard deviation, range between 9.72 and $10.37 \mathrm{~mm}$. To quantify the error linked to TDR interpolation, the water stock was calculated from ERT data, based on four local values only (corresponding to TDR probes depths, i.e. $10 \mathrm{~cm}, 30 \mathrm{~cm}, 70 \mathrm{~cm}$ and $125 \mathrm{~cm}$ ), and then interpolated as for TDR measurements. When only using four local measurements for estimating water storage, the deviation between TDR and ERT water stock ranged between $1.46 \mathrm{~mm}$ to $8.43 \mathrm{~mm}$. The ERT SWC, based on four local values, was then closer to the TDR water stock, especially at the beginning of the ERT measurement time. We conclude that the difference between ERT and TDR water stock is partly due to the spatial interpolation between TDR probes.

The error associated to the ERT storage was estimated by checking the mass balance in Eq. (12) for eight periods between our ERT measurement times. The black line in Fig. 6 represents the difference between the input and

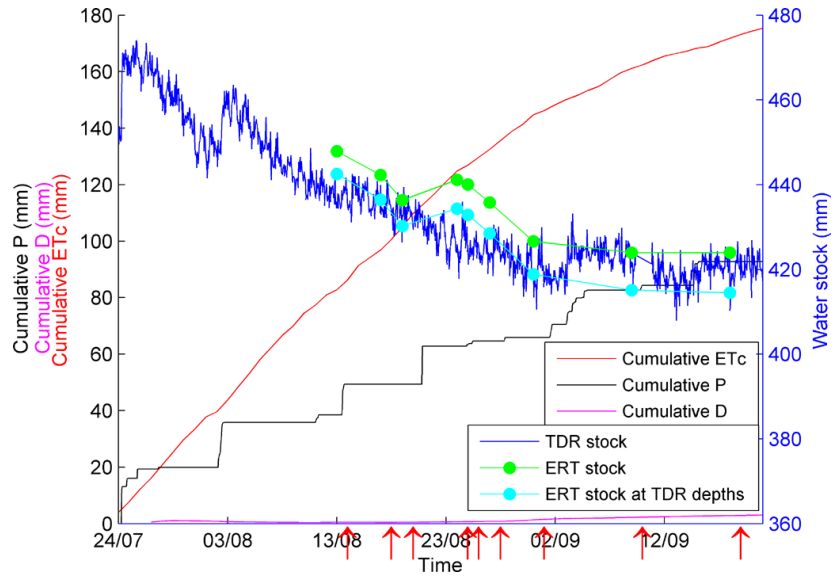

Fig. 5. Boundary conditions and water stock during field experimental time. Cumulative $P$ (black), cumulative ETC (red), cumulative $D$ (pink) with positive values corresponding to capillary rise and negative values to drainage, TDR water stock evolution (blue), ERT water stock (green with circles) and water stock considering ERT SWC at the four TDR depths $(10 \mathrm{~cm}, 30 \mathrm{~cm}, 70 \mathrm{~cm}$ and $125 \mathrm{~cm}$ ) and integrated as for TDR water stock (cyan circle). Red arrows represent the ERT measurement days.

stock change and the output. If there is no error in the different variables of balance, and if the water stock calculated with the ERT measurement is correct, the black line should be equal to zero. For most of the dates, the water balance was close to zero (the deviation was between $0.01 \mathrm{~mm}$ and $3.01 \mathrm{~mm}$ ), indicating a very good estimate of all the mass balance terms. The small difference could be associated (i) to the ERT uncertainty due to the use of an empiric pedoelectrical relationship (Laloy et al., 2011) and the imperfect inversion of ERT data (non-unique solution) (LaBrecque et al., 1996), and (ii) to errors associated to the other mass balance terms. The water balance calculated between 19 and 24 August 2009 was quite high and equal to $-11.92 \mathrm{~mm}$. This could be due to an underestimation of the rainfall occurring on 20 August 2009. Indeed, this was an intensive rainfall event $(13.5 \mathrm{~mm}$ in $12 \mathrm{~min})$ that could be miscalculated by the automatic tipping bucket rainfall gauge. This type of gauge usually underestimates the high rainfall by not considering the loss of water during the bucket rotation (Marsalek, 1981; Vasvári, 2005). Moreover, this stormy event may generate spatially high, variable rainfall distribution. By comparing the rainfall given by 2 meteorological stations located at $1.3 \mathrm{~km}$ from each other, for this rainy event a difference of rainfall of $4.2 \mathrm{~mm}$ was observed.

\subsubsection{Comparison between SWC measured by TDR and ERT}

Figure 7 compares the average (full markers), maximum and minimum (open markers) SWC obtained by TDR and by ERT at the four TDR depths for the row and inter-row 


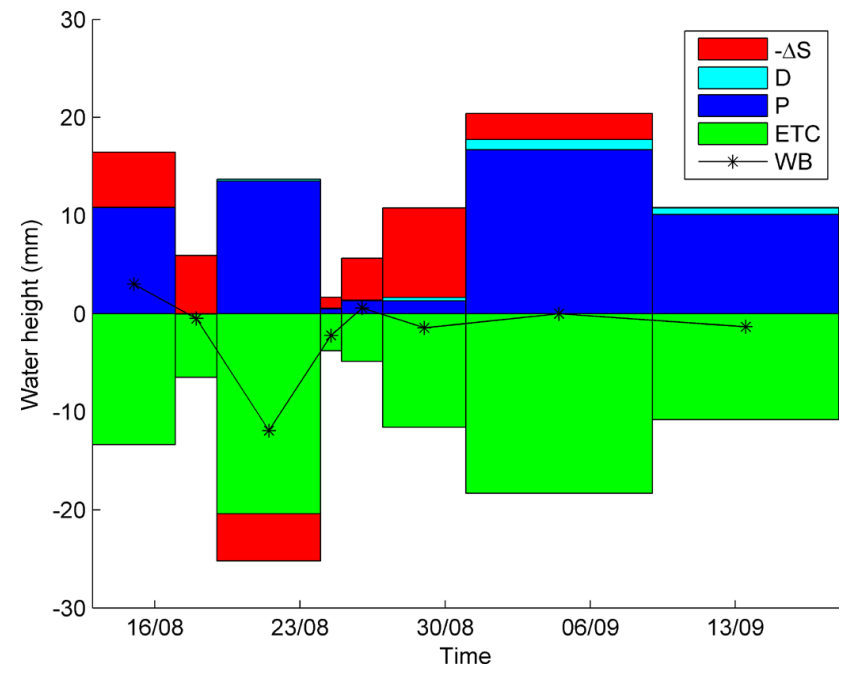

Fig. 6. Water balance (WB) between the nine ERT measurement times calculated with Eq. (12). Input includes rainfall, $P$ in $\mathrm{mm}$ (blue); capillary rise, $D$ in mm (cyan); and the output is the ETC in $\mathrm{mm}$ (green). The water stock variation, $-\Delta S$ in $\mathrm{mm}$ (red), is positive when SWC decreases and negative for an increase of SWC. The black line (WB) corresponds to the difference between the input and stock change and the output.

measurements together. The quality of the pedoelectrical relationship is demonstrated by the 1 to 1 correlation line $\left(R^{2}=0.98\right)$. The range between maximum and minimum values illustrates the SWC horizontal variability between TDR probes $(4$ probes at $10 \mathrm{~cm}, 30 \mathrm{~cm}$ and $70 \mathrm{~cm}$ and 2 probes at $125 \mathrm{~cm}$ depth) and between ERT SWC. At $10 \mathrm{~cm}$ depth, the difference between the maximum and minimum of SWC at each depth and time ranged from $0.0234 \mathrm{~cm}^{3} \mathrm{~cm}^{-3}$ to $0.0925 \mathrm{~cm}^{3} \mathrm{~cm}^{-3}$ for TDR measurements, and from $0.1142 \mathrm{~cm}^{3} \mathrm{~cm}^{-3}$ to $0.1661 \mathrm{~cm}^{3} \mathrm{~cm}^{-3}$ for ERT measurements. At $125 \mathrm{~cm}$ depth, the deviation was smaller and never exceeded $0.0221 \mathrm{~cm}^{3} \mathrm{~cm}^{-3}$ for either method. The maximum difference of SWC with TDR was in the same range as the maximum SWC difference obtained with neutron probes by Hupet and Vanclooster (2005) in a similar field with maize. The higher deviation for ERT than for TDR measurements can be explained by the higher spatial resolution of ERT measurements and thus by the discrimination of more SWC heterogeneities, especially visible in the first soil horizon. The results support the use of ERT to quantify the SWC spatial variability.

The evolution of SWC at four depths during the experimental period is shown in Fig. 8. The shaded envelopes encompass the spatial variability associated with the two TDR probes of each depth for the row or inter-row areas, except at 125-cm depth, where only one probe was present for the row and another one for the inter-row area. For each depth and area, the SWC measurements obtained by ERT are plotted.

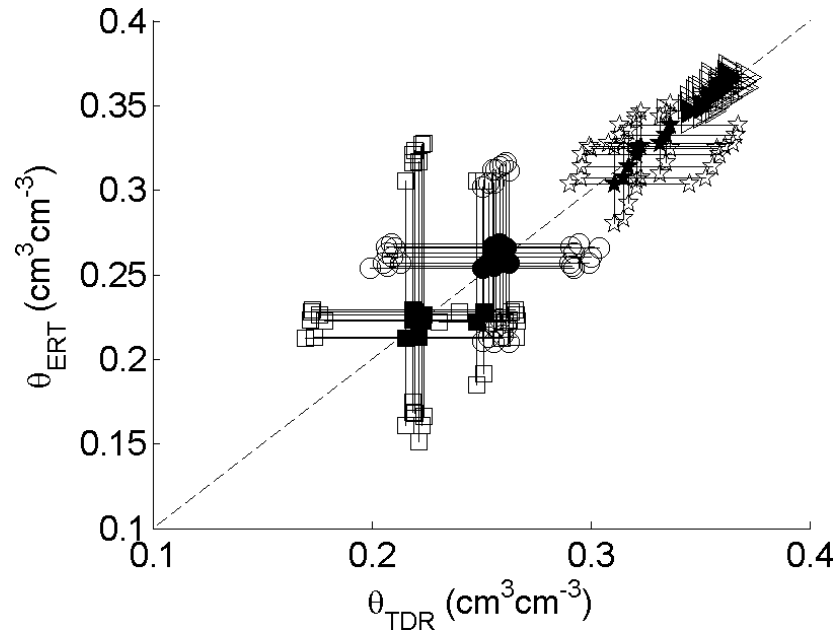

Fig. 7. Mean SWC measured by TDR and ERT at the 4 TDR measurement depths. The full markers correspond to the mean SWC and the open markers to the minimum and maximum SWC for each ERT measurement time for the same depths. The squares are for 10-cm depth, the circles for 30-cm depth, the stars for 70-cm depth and the triangles for $125-\mathrm{cm}$ depth. The dotted line corresponds to the $1: 1$ correlation line.

The agreement between TDR and ERT SWC was generally good (for the maize rows: RMSE $=0.0170 \mathrm{~cm}^{3} \mathrm{~cm}^{-3}$ and for the inter-rows: RMSE $=0.0129 \mathrm{~cm}^{3} \mathrm{~cm}^{-3}$ ). For the three upper depths, there is always an overlap between the ERT SWC plus one standard deviation and the envelope of minimum and maximum TDR SWC, except for the last two ERT measurements at $10 \mathrm{~cm}$ under the maize rows. These two measurements were realized after a rainy event, which probably revealed the within-field SWC variability. At $125 \mathrm{~cm}$ depth, ERT SWC was slightly different than TDR SWC, with a maximum difference of $0.0149 \mathrm{~cm}^{3} \mathrm{~cm}^{-3}$.

This difference is smaller than the error associated with the TDR calibration, and is similar to the error associated with pedoelectrical relationship. Brunet et al. (2010) compared the water content and water content deficit obtained from ERT with local measurements made with TDR at ten different times. Their comparison showed that ERT and TDR water content values globally exhibited the same temporal pattern, but with sometimes absolute differences up to $0.05 \mathrm{~cm}^{3} \mathrm{~cm}^{-3}$, which is acceptable but higher than what was observed in this study.

Figures 6, 7 and 8 demonstrate that the ERT methodology reasonably estimated the SWC at the field scale and gave comparable results to the TDR that is considered by many authors as an accurate way to measure SWC (Huisman et al., 2001; Robinson et al., 2003; Walker et al., 2004). 


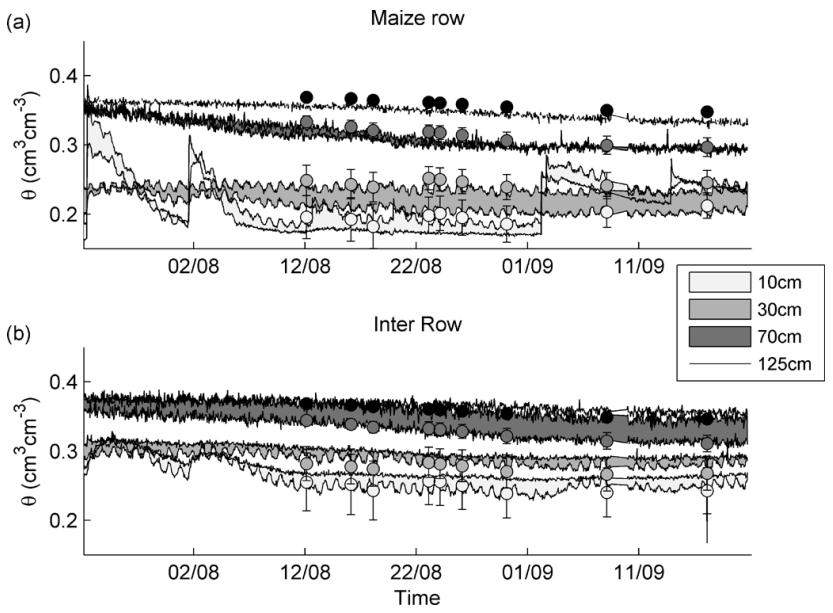

Fig. 8. Evolution of SWC at the four TDR measurement depths. The filled areas correspond to the SWC range based on two probe measurements in the row area (a) or in the inter-row area (b). At $125-\mathrm{cm}$ depth, only one probe was situated in the row area and one in the inter-row area. The circles are the ERT measurements at the same depth and at the corresponding time, and the bars are the mean \pm one standard deviation for the corresponding ERT measurements. Light grey circles and filled areas are for $10 \mathrm{~cm}$, middle grey for $30 \mathrm{~cm}$, dark grey for $70 \mathrm{~cm}$, and black for $125 \mathrm{~cm}$.

\subsection{Processes inducing SWC distribution}

\subsubsection{SWC spatial variability}

Figure 9 presents the normalized logarithmic coverage of the 3-D ERT inversion model, calculated with Eq. (7). One vertical section passing by three ERT electrodes sticks ( $y=$ $0.05 \mathrm{~m}$, Fig. 9a) and two horizontal sections $(z=-0.15 \mathrm{~m}$, Fig. 9b and $z=-1.4 \mathrm{~m}$, Fig. 9c) were chosen as representative examples. We observed that the coverage decreases with the distance from the electrodes and that the staggered position of the ERT electrodes did not deform the coverage distribution. The coverage appears to remain relatively high in the whole soil volume (Fig. 9a) thanks to the combination of surface and deep stick electrodes. Although the coverage was the lowest in the bottom of the soil volume, TDR measurements showed that the SWC variability was also lower in those depths (Figs. 7 and 8). Huge resolution is therefore not so important in the deep soil horizon.

Figure 10 shows three-dimensional SWC distributions for the seventh ERT measurement (31 August 2009). The irregular and non-horizontal isosurfaces illustrate the heterogeneity of the 3-D SWC distribution. The maize rows, perpendicular to the $\mathrm{x}$-axis at $0.6 \mathrm{~m}$ and $1.35 \mathrm{~m}$, seem to influence the drying pattern as observed by Hupet and Vanclooster (2005), amongst others. To quantify the maize row effect on SWC spatial variability, 2-D maps of the coefficient of variation of the SWC $(\mathrm{CV})$ were developed following the maize rows ( $\mathrm{y}$ direction, visible on $\mathrm{X}$-axis) and perpendicular to the maize rows (x-direction, visible on y-axis) (Fig. 11).
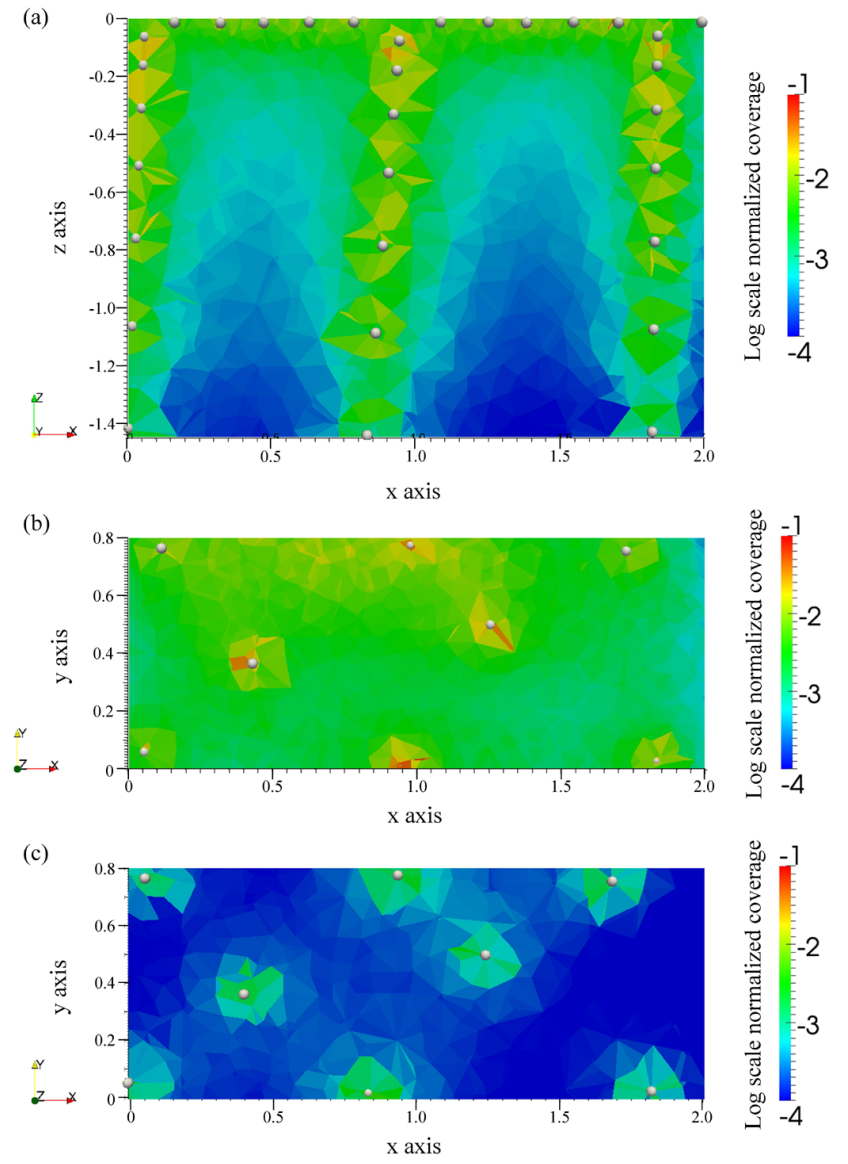

Fig. 9. Normalized coverage sections at $y=0.05 \mathrm{~m} \mathrm{(a),} z=$ $-0.15 \mathrm{~m}(\mathbf{b})$, and $z=-1.4 \mathrm{~m}$ (c) of the 3-D ERT inversion model. The coverage was calculated using Eq. (7). The white spheres represent the electrodes in the considered sections.

The distribution of $\mathrm{CV}$ was similar for the nine measurement times. The $\mathrm{CV}$ was higher in the topmost soil horizon for the $\mathrm{x}$ and $\mathrm{y}$-directions, where SWC was between 0.123 and $0.328 \mathrm{~cm}^{3} \mathrm{~cm}^{-3}$ (Fig. 8). Generally, the CV was lower on the $\mathrm{x}$-axis (in the maize rows direction) for the whole soil profile. In contrast, the $\mathrm{CV}$ on the $\mathrm{y}$-axis, considering alternation of maize rows and inter-rows, was relatively high with a decrease of $\mathrm{CV}$ with depth.

\subsubsection{SWC evolution during the late growing season of maize}

Two-dimensional maps of average SWC distributions along $y$-axis (visible on the $\mathrm{x}$-axis) were realized, considering the relatively low $\mathrm{CV}$ in that direction. The maize row/inter-row effect could then be observed on the y-average SWC distribution at 9 different dates (Fig. 12). A contrast of SWC between row and inter-row areas along the whole experimental period is observed. The soil is drier under maize rows and the difference between the middle of the row and the middle of the inter-row area at the same depths and times reached 


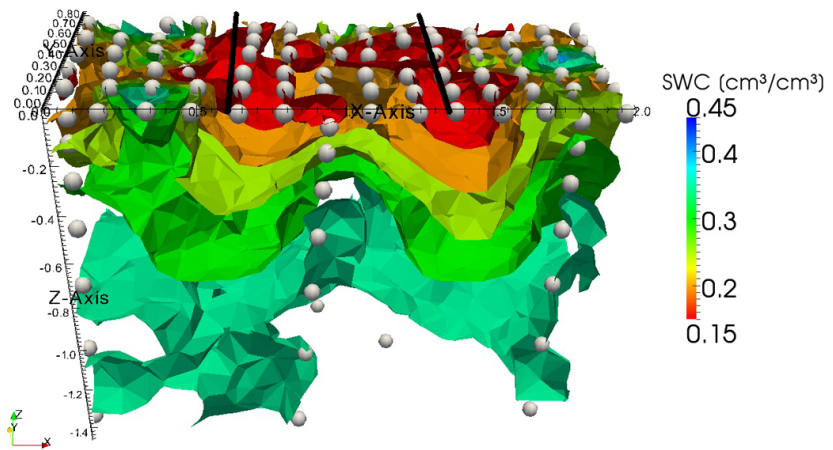

Fig. 10. Three-dimensional volumetric SWC for the ERT experimental plot for the seventh ERT measurement time (31 August 2009). The surfaces are isosurfaces of equal water content. The isosurfaces represent the volumetric SWC at $0.15\left(\mathrm{~cm}^{3} \mathrm{~cm}^{-3}\right), 0.2$ $\left(\mathrm{cm}^{3} \mathrm{~cm}^{-3}\right), 0.25\left(\mathrm{~cm}^{3} \mathrm{~cm}^{-3}\right), 0.3\left(\mathrm{~cm}^{3} \mathrm{~cm}^{-3}\right), 0.35\left(\mathrm{~cm}^{3} \mathrm{~cm}^{-3}\right)$. The black lines correspond to the maize row positions and the white spheres represent the electrodes.

$0.181 \mathrm{~cm}^{3} \mathrm{~cm}^{-3}$ in the first soil horizon (19 August 2009), and never exceeded $0.09 \mathrm{~cm}^{3} \mathrm{~cm}^{-3}$ in the third soil horizon. During the experimental period, the SWC decreased in the second and third soil horizons, especially under the maize rows, which generated a specific drying pattern. At the end of experimental period, the drying pattern was influenced down to the third soil horizon by the maize rows. Michot et al. (2003), Hupet and Vanclooster (2005) and Srayeddin and Doussan (2009) observed similar patterns in the maize field due to root water uptake (Michot et al., 2001).

Although drying fronts went down with time, the general drying pattern (due to alternation of row/inter-row) remained, with dry zones under the maize rows and at the soil surface, even after consequent rainfall events (for instance $24 \mathrm{Au}$ gust, 9 September and 18 September 2009). As shown in the next section, we suggest that the rainfall was not sufficient to change the SWC pattern created by root water uptake.

The root impact profiles realized at three different dates are shown in Fig. 13. The number of root impacts increases with time, but the spatial distribution remains similar. The root impacts were denser in the upper soil layer with a decrease at the plough pan layer mainly visible in the two first root profiles. The roots were more present under the maize rows than between the maize rows. Li et al. (2002) observed that in the well-watered soil profile, the spatial distribution of the roots mainly determines the typical pattern of root extraction, in addition to the fact that the roots near the plant base are more effective than those farther away. On 13 and 27 August and on 18 September 2009, the depth of the patterns of SWC (Fig. 12a, f and i) affected by maize rows reached (and locally exceeded) the maximum measurement depth of roots distribution (1m depth) (Fig. 13). Between 13 and 27 August 2009 and between 27 August and 18 September 2009, the drying front went deeper, while the driest zones remained under the maize rows. In the meantime, root

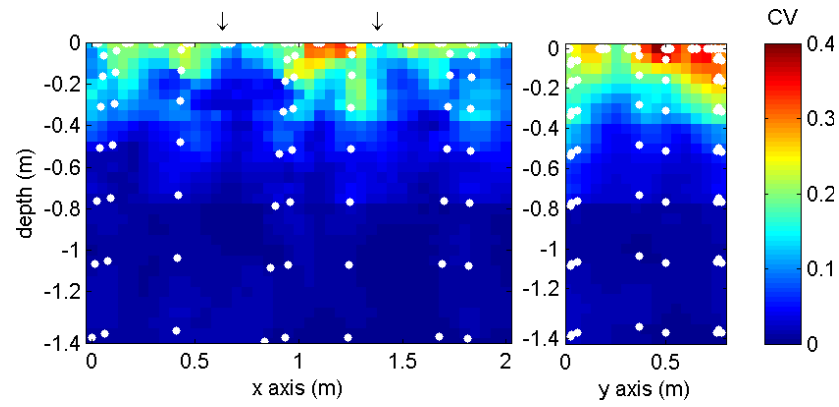

Fig. 11. SWC coefficient of variation for the first ERT measurement time (13 August 2009) on the x-axis (left), the y-axis (right). The arrows on the $\mathrm{x}$-axis figure represent the maize row positions. The white dots correspond to the electrode positions.
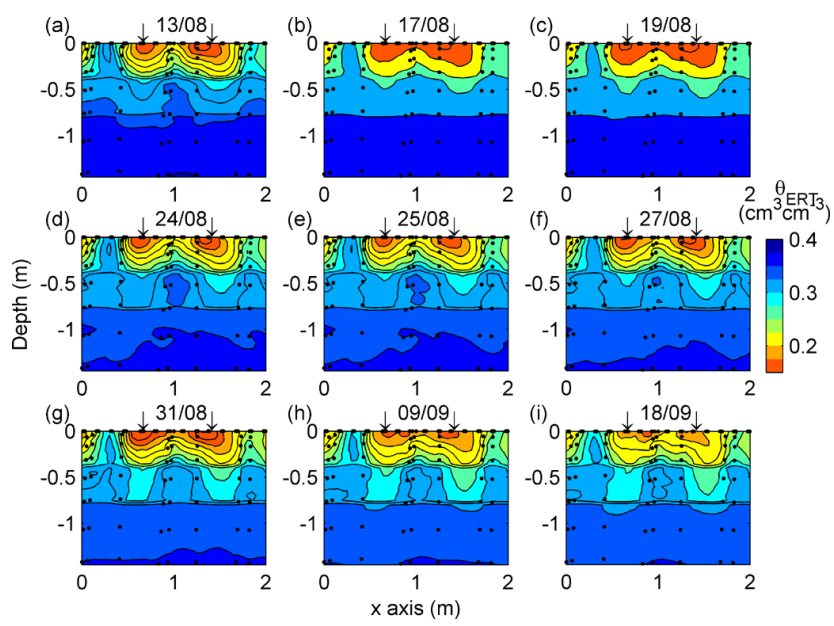

Fig. 12. Two-dimensional SWC distribution obtained by ERT on (a) 13 August 2009, (b) 17 August 2009, (c) 19 August 2009, (d) 24 August 2009, (e) 25 August 2009, (f) 27 August 2009, (g) 31 August 2009, (h) 9 September 2009, (i) 18 September 2009. The scale is the SWC $\left(\mathrm{cm}^{3} \mathrm{~cm}^{-3}\right)$. The arrows indicate the maize row positions.

impacts increased homogeneously in the whole soil profile, keeping the same shape of root distribution.

Between the first (13 August 2009) and the last (18 September 2009) ERT measurement times, SWC decreased in the whole soil profile, except in the first $20 \mathrm{~cm}$ near the soil surface (Fig. 14). The rainfall was not sufficient to compensate crop transpiration and the water stock decreased from $448 \mathrm{~mm}$ to $424 \mathrm{~mm}$ as observed in the water mass balance (Fig. 6). The increase of SWC at the surface was due to a rainfall event occurring at the end of the growing season. In the second soil horizon, a decrease of SWC with depth is observed going from $0.015 \mathrm{~cm}^{3} \mathrm{~cm}^{-3}$ to $0.038 \mathrm{~cm}^{3} \mathrm{~cm}^{-3}$. At the interface between the second and third soil horizon, the depletion curve is discontinuous and relatively uniform at around $0.02 \mathrm{~cm}^{3} \mathrm{~cm}^{-3}$ in the third soil horizon. The SWC decrease was mainly observed in the second and third soil 

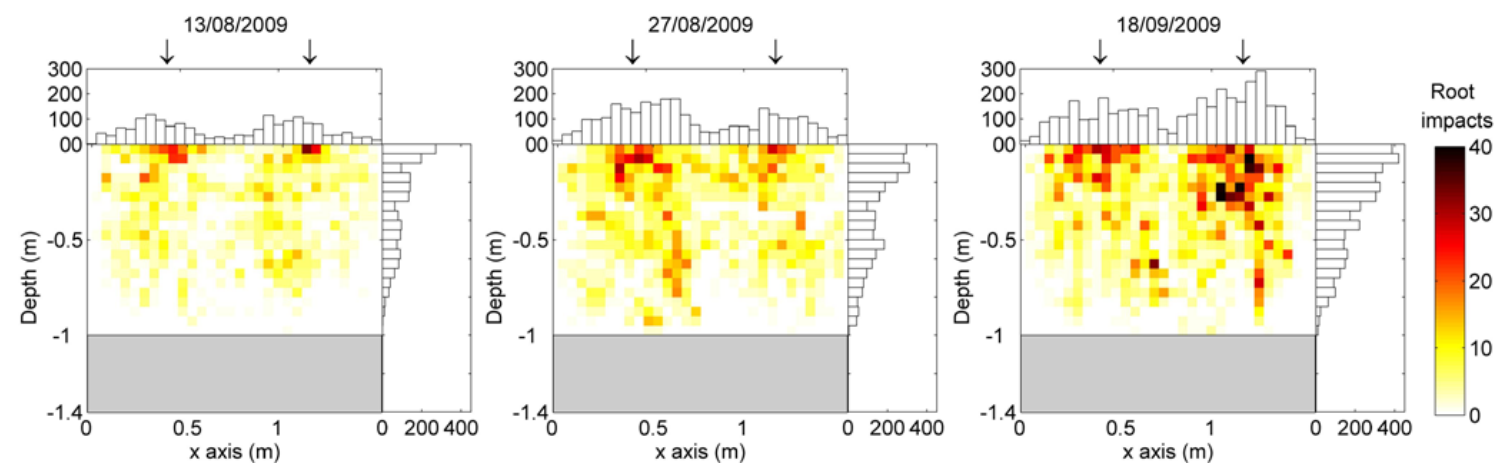

Fig. 13. Root profiles obtained by Tardieu's method. The coloured squares correspond to the number of root impacts, resulting in a 2-D distribution of roots. The colour scale represents the number of root impacts. The horizontal and vertical histograms correspond to the number of root impacts in the $\mathrm{x}$ and $\mathrm{y}$-directions, respectively. It helps to compare the number of impacts in the row and inter-row areas and for the different depths. The grey area delimited the zone without measurements. The arrows indicate the maize rows position.

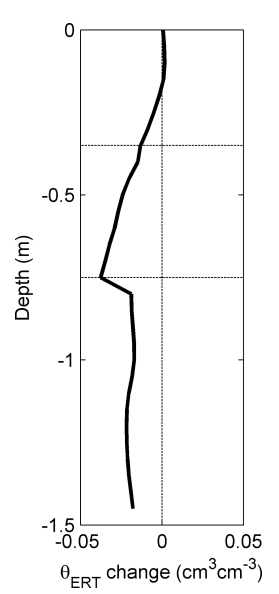

Fig. 14. SWC change for the whole soil profile between the first day of ERT measurement (13 August 2009) and the last day (18 September 2009). Negatives values mean a decrease of SWC during the experimental time and positives values an increase of SWC. The vertical dotted line is the limit between increase and decrease of SWC. The horizontal dotted lines correspond to the limits of the soil horizons.

horizons, while most of the roots were observed in the first soil horizon. Because soil water flow may compensate root water uptake, the shape of the soil water depletion profile does not reflect the root impacts distribution, as also observed by Garré et al. (2011) and Vandoorne et al. (2012). In our case, this discrepancy was due to the fact that (i) most of the roots (Fig. 13) were located in an initially drier zone (Fig. 12) and (ii) the late rainfall event increased the SWC mainly in the first soil horizon under the maize rows (Fig. 8). This initial and boundary conditions for our measurement period determined the SWC distribution and the observed SWC decrease.

\subsubsection{Effect of root water uptake and rainfall on SWC changes}

To investigate whether root water uptake increases or decreases the field-scale SWC variability, the 2-D SWC evolution between five consecutives ERT measurement times was analysed (Fig. 15). The SWC change was quantified during two small periods, P1 (between 25 and 27 August 2009) and P2 (between 27 and 31 August 2009), with negligible rainfall $(P=1.3 \mathrm{~mm})$, and two longer periods, $\mathrm{P} 3$ (between 31 August and 9 September 2009) and P4 (between 9 and 18 September 2009) with consequent rainfall events ( $P=16.7 \mathrm{~mm}$ and $10.1 \mathrm{~mm}$, respectively).

During P1 and P2, a slight decrease of SWC in the soil profile was observed with ERT. During P1 (Fig. 15b), the SWC depletion was mainly located in the first soil horizon. During P2 (Fig. 15c), the SWC decreased mainly under the interrows in the two upper soil horizons, contrary to Michot et al. (2003) who observed a decrease of SWC under the maize rows. In contrast to that study, the SWC at the surface and under the maize rows was relatively low at the beginning of the period. Therefore SWC depletion occurred in the deeper zones and in the inter-row area.

Despite the rainfall events occurring during P3 and P4, the total soil water storage decreased (Fig. 6). Local SWC diminutions were principally observed in the inter-row area of the first soil horizon and everywhere in the second and third soil horizons (Fig. 15d, e, and f). In contrast, the increase of SWC was mainly located in the first soil horizon and under the maize rows, where the SWC was the lowest before the rainfall (Fig. 12). Michot et al. (2003) mentioned that selective infiltration occurs under the maize plants due to preferential directions of water flux and the role of the aerial part of the maize plant to catch water, create stem flow and promote infiltration under the maize plant. By comparing the TDR time series between the row and inter-row regions, we could check this hypothesis. A quick increase of 

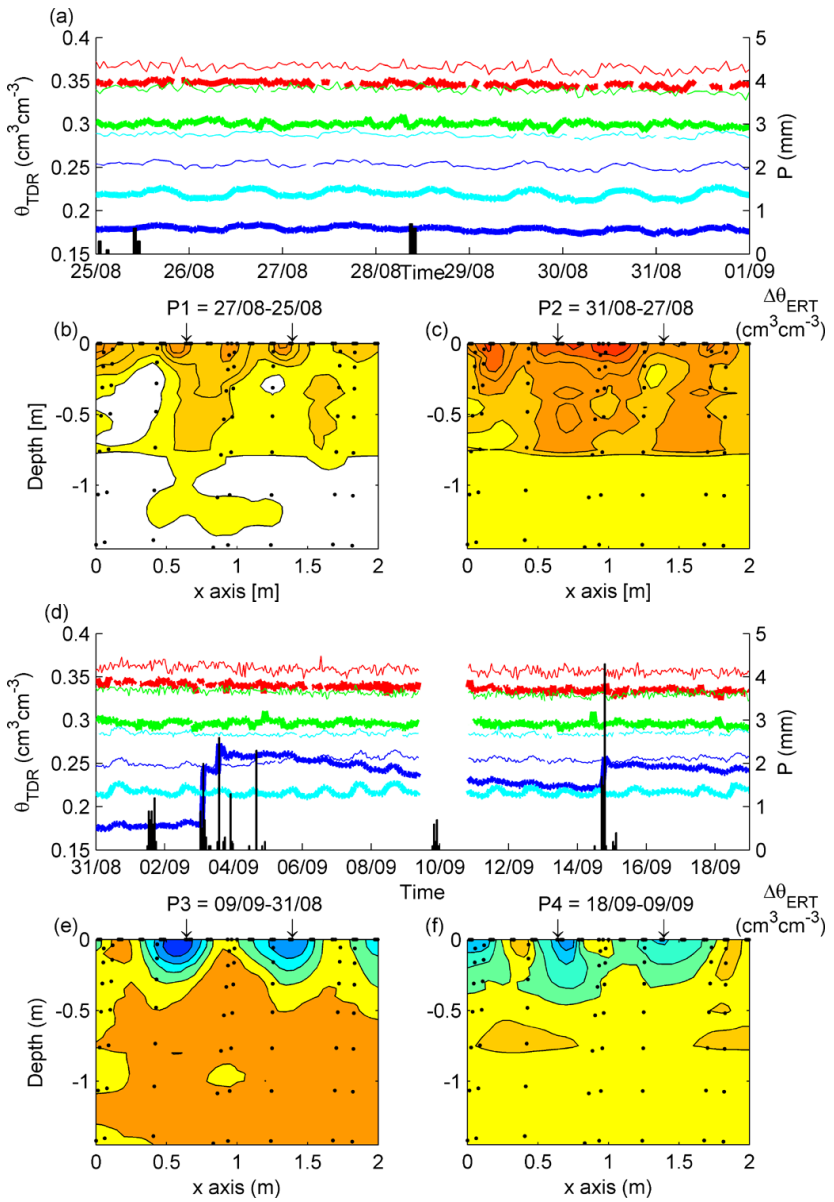

Fig. 15. TDR SWC content evolution during (a) P1 (25 to $27 \mathrm{Au}-$ gust 2009) and P2 (27 to 31 August 2009) and (d) P3 (31 August to 9 September 2009) and P4 (9 to 18 September 2009). The bold lines correspond to the maize row TDR measurements and the thin lines to inter-row measurements. Blue is for $10 \mathrm{~cm}$ depth, cyan for $30 \mathrm{~cm}$ depth, green for $70 \mathrm{~cm}$ depth and red for $125 \mathrm{~cm}$ depth. The 2-D figures represent the ERT SWC differences for P1 (b), P2 (c), P3 (e) and P4 (f). The colour scale corresponds to the SWC changes $\left(\mathrm{cm}^{3} \mathrm{~cm}^{-3}\right)$. Negatives values mean a decrease of SWC and the positives values mean an increase of SWC. The arrows indicate the maize rows position.

SWC under the maize rows at $10-\mathrm{cm}$ depth just a few minutes after rainfall event start was observed (Fig. 15d). Then the row SWC at $10 \mathrm{~cm}$ reached and eventually exceeded the level of SWC of the inter-row. After the rainfall, SWC below the maize rows of the first depth decreased again, while almost no SWC change was observed by TDR in other locations. This decrease thus reflects the impact of root water uptake rather than lateral soil water redistribution. The second ERT measurements were realized 5 and 3 days after the rainfall events for $\mathrm{P} 3$ and $\mathrm{P} 4$, respectively. Although a few days passed between the rainfall event and ERT measurement, the SWC increase zone was still located below the maize rows. However, the drying patterns remained during these two periods (Fig. 12h and i), confirming that the rainfall volumes were not sufficient to impact the general SWC patterns and that lateral redistribution from the maize rows to the inter-rows hardly occurred in this maize field during the whole experimental period.

With TDR measurements, the dynamics of SWC can be monitored, but the spatial distribution is limited and the small changes of SWC are not really visible. It is therefore advantageous to combine TDR and ERT measurements to assess the SWC distribution dynamics at the field scale.

By investigating the dynamics of SWC distribution we observed that both root water uptake and rainfall were influencing the SWC variability. Root water uptake, by reinforcing drying patterns, generates variability. In contrast, rainfall increases the SWC under the maize rows, where the soil is the driest, by preferential infiltration. This preferential infiltration tends to homogenize the SWC, as showed by the TDR measurements at $10 \mathrm{~cm}$ where the $\mathrm{SWC}$ under the maize row reaches the SWC under the inter-row when a significant rainfall occurred (Fig. 15d).

\section{Conclusions}

We conducted a field experiment (i) to validate an ERT methodology to determine the 3-D SWC distribution at the plot scale and (ii) to investigate how rainfall and root water uptake affect the SWC dynamics by combining ERT and TDR measurements.

The validation of ERT to derive the 3-D distribution of SWC was performed using a global mass balance method and a comparison between TDR and ERT measurements. The water stock given by ERT measurements provided a good estimate of the water storage during the experimental time (13 August to 18 September 2009), except for one time (between 19 and 25 August 2009), when the total rainfall for a storm event could have been underestimated. The water stock quantification for TDR and ERT highlighted the improvement expected with ERT due to its better spatial resolution as compared to TDR measurements.

By comparing averaged SWC measured by TDR and ERT at four depths, we demonstrated the accuracy of ERT for estimating the mean $\left(R^{2}=0.98\right)$ and the variability of the SWC. It was observed that the SWC spatial variability was higher in the first soil horizon where the soil was drier and more roots were present than in the two other soil horizons. A higher $\mathrm{CV}$ of SWC distribution was observed in the direction perpendicular (visible on y-axis) to the rows than parallel (visible on X-axis). We confirmed that the SWC distribution is influenced by the maize row pattern.

During ERT measurement period, the global SWC mainly decreased in the deeper soil layers, where the soil was initially wetter. In the second and third soil horizons, the SWC decreased about $0.038 \mathrm{~cm}^{3} \mathrm{~cm}^{-3}$ and $0.02 \mathrm{~cm}^{3} \mathrm{~cm}^{-3}$, respectively. Because the upper soil layer was already relatively dry 
at the beginning of ERT measurement period and the soil water flow may compensate root water uptake, the shape of the soil water depletion profile did not reflect the root distribution.

During short periods ( 2 and 3 days) with negligible rainfall $(P=1.3 \mathrm{~mm})$, the SWC decrease was slightly visible and occurred in the first and second soil horizon, mainly in the inter-rows area (Fig. 15b and c). During longer periods (9 days) with consequent rainfall $(P=16.7 \mathrm{~mm}$ and $10.1 \mathrm{~mm}$ respectively), the SWC decrease was mainly visible in the second and third soil horizon (Fig. 15e and f). The stem flow and/or the preferential infiltration along maize roots increased the SWC mainly under the maize rows in the first soil horizon, which is the driest area of the soil profile. Yet, the local increase of SWC was not sufficient to modify the general row/inter-row pattern, which remained visible for the whole period. Lateral soil water redistribution from the maize interrows to the rows was hardly visible during the season probably due to continuous water uptake in the rooting zone and the low hydraulic conductivity of the dry soil.

ERT allowed for the observation of the SWC distribution evolution with a good spatial resolution, while TDR helped to monitor the evolution of SWC with a good temporal resolution. The combination of both methods therefore provides a good tool for investigating SWC distribution dynamics at the plot scale.

Further studies should focus on the quantification of the impact of root water uptake and rainfall on the dynamics of SWC distribution. This could be achieved by more regular ERT SWC measurements considering the meteorological conditions. Coupled with better measurements of boundary fluxes, it could help to more accurately characterize the processes generating and decreasing SWC heterogeneity, and thus to improve SWC distribution understanding and predictions.

Acknowledgements. This study was done with the financial support of a Research Grant of the Fund for Scientific Research (Belgium) (F.N.R.S./FRIA). The authors acknowledge the technicians for their assistance during the field preparation and monitoring. Special thanks to Sarah Garré and Frédéric Nguyen for their relevant suggestions and fruitful discussions.

Edited by: D. Mazvimavi

\section{References}

Allen, R. G., Pereira, L. S., Raes, D., and Smith, M.: Crop evapotranspiration - Guidelines for computing crop water requirements, FAO Irrigation and Drainage FAO, Rome, 1998.

Archie, G. E.: The electrical resistivity log as an aid in determining some reservoir characteristics, T. Am. I. Min. Met. Eng., 146, 54-67, 1942.
Bing, Z. and Greenhalgh, S. A.: Cross-hole resistivity tomography using different electrode configurations, Geophys. Prospect., 48, 887-912, 2000.

Binley, A. and Kemna, A.: DC resistivity and induced polarization method, in: Hydrogeophysics, edited by: Springer, Netherlands, 129-156, 2005.

Binley, A., Henry-Poulter, S., and Shaw, B.: Examination of solute transport in an undisturbed soil column using electrical resistance tomography, Water Resour. Res., 32, 763-769, 1996.

Brunet, P., Clément, R., and Bouvier, C.: Monitoring soil water content and deficit using Electrical Resistivity Tomography (ERT) A case study in the Cevennes area, France, J. Hydrol., 380, 146153, 2010.

Cassiani, G., Bruno, V., Villa, A., Fusi, N., and Binley, A. M.: A saline trace test monitored via time-lapse surface electrical resistivity tomography, J. Appl. Geophys., 59, 244-259, 2006.

Clothier, B. E. and Green, S. R.: Rootzone processes and the efficient use of irrigation water, Agr. Water Manage., 25, 1-12, 1994.

Coelho, E. F. and Or, D.: Root distribution and water uptake patterns of corn under surface and subsurface drip irrigation, Plant Soil, 206, 123-136, 1999.

Devitt, D. A. and Smith, S. D.: Root channel macropores enhance downward movement of water in a Mojave Desert ecosystem, J. Arid Environ., 50, 99-108, 2002.

Flury, M., Leuenberger, J., Studer, B., and Fluhler, H.: Transport of anions and herbicides in a loamy and a sandy field soil, Water Resour. Res., 31, 823-836, 1995.

Friedel, S.: Resolution, stability and efficiency of resistivity tomography estimated from a generalized inverse approach, Geophys. J. Int., 153, 305-316, 2003.

Garré, S., Huisman, S., and Weihermüller, L.: Manual for TDR calibration, Agrosphere Institute, ICG IV, Forschungszentrum Jülich GmbH, 52425 Jülich, Germany, 1-18, 2008.

Garré, S., Koestel, J., Günther, T., Javaux, M., Vanderborght, J., and Vereecken, H.: Comparison of heterogeneous transport processes observed with electrical resistivity tomography in two soils, Vadose Zone J., 9, 336-349, 2010.

Garré, S., Javaux, M., Vanderborght, J., Pagès, L., and Vereecken, H.: Three-dimensional electrical resistivity tomography to monitor root zone water dynamics, Vadose Zone J., 10, 412-424, 2011.

Garré, S., Günther, T., Diels, J., and Vanderborght, J.: Evaluating experimental design of ERT for soil moisture monitoring in contour hedgerow intercropping systems, Vadose Zone J., 11, 14 pp., doi:10.2136/vzj2011.0186, 2012.

Gish, T. J., Gimenez, D., and Rawls, W. J.: Impact of roots on ground water quality, Plant Soil, 200, 47-54, 1998.

Green, S. R., Kirkham, M. B., and Clothier, B. E.: Root uptake and transpiration: From measurements and models to sustainable irrigation, Agr. Water Manage., 86, 165-176, 2006.

Günther, T.: Inversion Methods and Resolution Analysis for the 2D/3D Reconstruction of Resistivity Structures from DC Measurements, University of Mining and Technology Freiberg, 2004.

Günther, T., Rücker, C., and Spitzer, K.: Three-dimensional modelling and inversion of dc resistivity data incorporating topography - II. Inversion, Geophys. J. Int., 166, 506-517, 2006.

Heimovaara, T. J.: Design of triple-wire time domain reflectometry probes in practice and theory, Soil Sci. Soc. Am. J., 57, 1410$1417,1993$. 
Huisman, J. A., Sperl, C., Bouten, W., and Verstraten, J. M.: Soil water content measurements at different scales: accuracy of time domain reflectometry and ground-penetrating radar, J. Hydrol., 245, 48-58, 2001.

Hupet, F. and Vanclooster, M.: Intraseasonal dynamics of soil moisture variability within a small agricultural maize cropped field, J. Hydrol., 261, 86-101, 2002.

Hupet, F. and Vanclooster, M.: Micro-variability of hydrological processes at the maize row scale: implications for soil water content measurements and evapotranspiration estimates, J. Hydrol., 303, 247-270, 2005.

Hupet, F., Bogaert, P., and Vanclooster, M.: Quantifying the localscale uncertainty of estimated actual evapotranspiration, Hydrol. Process., 18, 3415-3434, 2004.

Jacques, D., Mohanty, B., Timmerman, A., and Feyen, J.: Study of time dependency of factors affecting the spatial distribution of soil water content in a field-plot, Phys. Chem. Earth. Pt. B, 26, 629-634, 2001.

Javaux, M., Schroder, T., Vanderborght, J., and Vereecken, H.: Use of a three-dimensional detailed modeling approach for predicting root water uptake, Vadose Zone J., 7, 1079-1088, 2008.

Kemna, A., Vanderborght, J., Kulessa, B., and Vereecken, H.: Imaging and characterisation of subsurface solute transport using electrical resistivity tomography (ERT) and equivalent transport models, J. Hydrol., 267, 125-146, 2002.

Koestel, J., Kemna, A., Javaux, M., Binley, A., and Vereecken, H.: Quantitative imaging of solute transport in an unsaturated and undisturbed soil monolith with 3-D ERT and TDR, Water Resour. Res., 44, W12411, doi:10.1029/2007WR006755, 2008.

Koestel, J., Vanderborght, J., Javaux, M., Kemna, A., Binley, A., and Vereecken, H.: Noninvasive 3-D Transport Characterization in a Sandy Soil Using ERT: 1. Investigating the Validity of ERT-derived Transport Parameters, Vadose Zone J., 8, 711-722, 2009a.

Koestel, J., Vanderborght, J., Javaux, M., Kemna, A., Binley, A., and Vereecken, H.: Noninvasive 3-D Transport Characterization in a Sandy Soil Using ERT: 2. Transport Process Inference, Vadose Zone J., 8, 723-734, 2009b.

Koumanov, K. S., Hopmans, J. W., and Schwankl, L. W.: Spatial and temporal distribution of root water uptake of an almond tree under microsprinkler irrigation, Irrigation Sci., 24, 267-278, 2006.

LaBrecque, D. J. and Yang, X.: Difference Inversion of ERT Data: a fast inversion method for 3-D in situ monitoring, J. Environ. Eng. Geophys., 6, 83-89, 2001.

LaBrecque, D. J., Miletto, M., Daily, W., Ramirez, A., and Owen, E.: The effects of noise on Occam's inversion of resistivity tomography data, Geophysics, 61, 538-548, 1996.

Laloy, E., Javaux, M., Vanclooster, M., Roisin, C., and Bielders, C. L.: Electrical resistivity in a loamy soil: identification of the appropriate pedo-electrical model, Vadose Zone J., 10, 1023-1033, 2011.

Li, Y., Wallach, R., and Cohen, Y.: The role of soil hydraulic conductivity on the spatial and temporal variation of root water uptake in drip-irrigated corn, Plant Soil, 243, 131-142, 2002.

Mallants, D., Jacques, D., Vanclooster, M., Diels, J., and Feyen, J.: A stochastic approach to simulate water flow in a macroporous soil, Geoderma, 70, 299-324, 1996.

Marsalek, J.: Calibration of the tipping-bucket raingage, J. Hydrol., 53, 343-354, 1981.
Merz, R., Blöschl, G., and Parajka, J.: Spatio-temporal variability of event runoff coefficients, J. Hydrol., 331, 591-604, 2006.

Michot, D., Dorigny, A., and Benderitter, Y.: Mise en évidence par résistivité électrique des écoulements préférentiels et de l'assèchement par le maïs d'un CALCICOL de Beauce irrigué, Earth Planet Sci., 332, 29-36, 2001.

Michot, D., Benderitter, Y., Dorigny, A., Nicoullaud, B., King, D., and Tabbagh, A.: Spatial and temporal monitoring of soil water content with an irrigated corn crop cover using surface electrical resistivity tomography, Water Resour. Res., 39, 1138, 2003.

Minet, J.: High-resolution soil moisture mapping by a proximal ground penetrating radar: A numerical, laboratory and field evaluation, $\mathrm{PhD}$ thesis, Faculté d'ingénierie biologique, agronomique et environnementale, Université catholique de Louvain, Louvain-la-Neuve (Belgium), available at: http://dial. academielouvain.be/handle/boreal:76830, 195 pp., 2011.

Mooney, S. J. and Morris, C.: Morphological approach to understanding preferential flow using image analysis with dye tracers and X-ray computed tomography, Catena, 73, 204-211, 2008.

Norbiato, D., Borga, M., Merz, R., Blöschl, G., and Carton, A.: Controls on event runoff coefficients in the eastern Italian Alps, J. Hydrol., 375, 312-325, 2009.

Oberdörster, C., Vanderborght, J., Kemna, A., and Vereecken, H.: Investigating preferential flow processes in a forest soil using time domain reflectometry and electrical resistivity tomography, Vadose Zone J., 9, 350-361, doi:10.1029/2004jb003569, 2010.

Oliveira, R. S., Bezerra, L., Davidson, E. A., Pinto, F., Klink, C. A., Nepstad, D. C., and Moreira, A.: Deep root function in soil water dynamics in cerrado savannas of central Brazil, Funct. Ecol., 19, 574-581, 2005.

Revil, A., Cathles, L. M., Losh, S., and Nunn, J. A.: Electrical conductivity in shaly sands with geophysical applications, J. Geophys. Res.-Sol. Ea., 103, 23925-23936, 1998.

Rhoades, J. D., Manteghi, N. A., Shouse, P. J., and Alves, W. J.: Soil electrical conductivity and soil salinity: new formulations and calibrations, Soil Sci. Soc. Am. J., 53, 433-439, 1989.

Robinson, D. A., Jones, S. B., Wraith, J. M., Or, D., and Friedman, S. P.: A review of advances in dielectric and electrical conductivity measurement in soils using time domain reflectometry, Vadose Zone J., 2, 444-475, 2003.

Rücker, C. and Günther, T.: The simulation of finite ERT electrodes using the complete electrode model, Geophysics, 76, 227-238, doi:10.1029/95WR02995, 2011.

Rücker, C., Günther, T., and Spitzer, K.: Three-dimensional modelling and inversion of dc resistivity data incorporating topography - I. Modelling, Geophys. J. Int., 166, 495-505, 2006.

Samouelian, A., Cousin, I., Tabbagh, A., Bruand, A., and Richard, G.: Electrical resistivity survey in soil science: a review, Soil Till. Res., 83, 173-193, 2005.

Schwartz, B. F., Schreiber, M. E., and Yan, T.: Quantifying fieldscale soil moisture using electrical resistivity imaging, J. Hydrol., 362, 234-246, 2008.

Sharp, R. E. and Davies, W. J.: Root growth and water uptake by maize plants in drying soil, J. Exp. Bot., 36, 1441-1456, 1985.

Slater, L., Binley, A. M., Daily, W., and Johnson, R.: Cross-hole electrical imaging of a controlled saline tracer injection, J. Appl. Geophys., 44, 85-102, 2000.

Slater, L., Binley, A., Versteeg, R., Cassiani, G., Birken, R., and Sandberg, S.: A 3D ERT study of solute transport in a large ex- 
perimental tank, J. Appl. Geophys., 49, 211-229, 2002.

Soil Atlas of Europe: European Soil Bureau Network, European soil bureau network, edited by: Jones, A., Montanarella, L., and Jones, R., European Commission, Office for official publications of the european communities, L-2995 Luxembourg, 128 pp., 2005.

Srayeddin, I. and Doussan, C.: Estimation of the spatial variability of root water uptake of maize and sorghum at the field scale by electrical resistivity tomography, Plant Soil, 319, 185-207, 2009.

Tardieu, F.: Analysis of the spatial variability of maize root density - II. Distances between roots, Plant Soil, 107, 267-272, 1988.

Teuling, A. J. and Troch, P. A.: Improved understanding of soil moisture variability dynamics, Geophys. Res. Lett., 32, 1-4, doi:10.1029/2002WR001616, 2005.

Topp, G. C., Davis, J. L., and Annan, A. P.: Electromagnetic Determination of Soil-water Content - Measurements In Coaxial Transmission-lines, Water Resour. Res., 16, 574-582, 1980.

Udphuay, S., Günther, T., Everett, M. E., Warden, R. R., and Briaud, J. L.: Three-dimensional resistivity tomography in extreme coastal terrain amidst dense cultural signals: Application to cliff stability assessment at the historic D-Day site, Geophys. J. Int., 185, 201-220, 2011.

van Genuchten, M. T.: Closed-form equarion for predicting the hydraulic conductivity of unsaturated soils, Soil Sci. Soc. Am. J., 44, 892-898, 1980.

Vandoorne, B., Beff, L., Lutts, S., and Javaux, M.: Root water uptake dynamics of cichorium intybus var. sativum under water-limited conditions, Vadose Zone J., 11, 16 pp., doi:10.2136/vzj2012.0005, 2012.
Vasvári, V.: Calibration of tipping bucket rain gauges in the Graz urban research area, Atmos. Res., 77, 18-28, 2005.

Walker, J. P., Willgoose, G. R., and Kalma, J. D.: In situ measurement of soil moisture: a comparison of techniques, J. Hydrol., 293, 85-99, 2004.

Waxman, M. H., and Smits, L. J. M.: Electrical conductivities in oilbearing shaly sands, Soc. Petrol. Eng. J., 243, 107-122, 1968.

Werban, U., Al Hagrey, S. A., and Rabbel, W.: Monitoring of rootzone water content in the laboratory by $2 \mathrm{D}$ geoelectrical tomography, J. Plant Nutr. Soil Sc., 171, 927-935, 2008.

Western, A. W., Grayson, R. B., Blöschl, G., and Wilson, D. J.: Spatial variability of soil moisture and its implications for scaling, in: Scaling methods in soil physics, edited by: Pachepsky, Y., Radcliffe, D. E., and Selim, H. M., CRC Press, Florida, 119-142, 2003.

Weynants, M.: Linking soil hydraulic properties to structure indicators : experiments and modelling, $\mathrm{PhD}$ thesis, Earth and Life Institute - Environmental Sciences, Université catholique de Louvain, Louvain-la-Neuve (Belgium), available at: http://dial.academielouvain.be/vital/access/ manager/Repository/boreal:75972?site_name=UCL (last access: 7 February 2013), 144 pp., 2011. 